Its diameter is $86 \mathrm{~cm}$ (34 in.). Telstar is an active communications satellite-designed to amplify and re-transmit the signals sent to it-and has operated with notable success. The first trans-Atlantic television pictures by satellite were transmitted from the station at Andover, Maine, and received at Goonhilly Down, Cornwall, and Lannion, Brittany, on the sixth rovolution of the satellite, within $16 \mathrm{hr}$. of launch.

\section{Tenth Pugwash Conference}

Further to the announcement of the tenth Pugwash Conference to be held in London during September 3-7, which appeared on p. 126 of the July 14 issue of Nature, the following information has been received:

British participants at the Conference will include Sir John Cockcroft, Master of Churchill College, Cambridge; Sir Howard Florey, Master of Queen's College, Oxford, and president of the Royal Society; Sir Julian Huxley; Lord Russell; Sir Charles Snow; and Sir George Thomson, Master of Corpus Christi College, Cambridge. The chairman at the opening session of the conference on September 3 will be Sir Nevill Mott, Master of Caius College, Cambridge, and director of the Cavendish Laboratory. Among Russians attending the conference may be included Academician Blagonravov, head of the Russian programme of space research; Prof. Emelyanov, head of the department responsible for atomic research in the Soviet Union and Russian delegate to the International Atomic Energy Agency in Vienna; I. V. Federov, secretary of the Moscow Academy of Sciences and at one time the leader of the Russian delegation to the test-ban talks at Geneva; Academicians $\mathrm{N}$. Semenov and I. Tamm, Nobel prizewinners in chemistry and physics; and Academician A. V. Topchiev, executive vice-president of the Moscow Academy of Sciences. The group from the United States will include Dr. D. G. Brennan, president of the Hudson Institute of New York, and an adviser to the U.S. Government on defence; Prof. Margaret Mead, the anthropologist; Dr. J. Oppenheimer, director of the Institute for Advanced Study at Princeton and once head of the Los Alamos laboratory of the Atomic Energy Commission; Dr. Linus Pauling; Dr. Alfred Sabin; and Dr. Victor Weisskopf, at present the director of the European Centre for Nuclear Research (CERN) at Geneva.

A discussion is to be included in the programme of the Conference of the suggestion that West Berlin should be made the site of an international centre for scientific research.

\section{The Journal of Catalysis}

The phenomena of new journals devoted to a single aspect of a science or technology have been of frequent occurrence in the past few years. While the prospect of the increasing number of publications one could reasonably be expected to have to scan has become somewhat alarming, it is nevertheless of great value to specialists to have available journals specific to their own field of work. It is on such grounds that one can welcome the new Journal of Catalysis, edited by J. H. de Boer and P. W. Selwood and published by Academic Press (1, No. 1; March 1962. Pp. 92. New York and London: Academic Press, Inc., 1962. Vol. 1 (6 issues), 1962: 18 dollars). The importance of the subject is one that merits this kind of treatment, but it is to be hoped that the editors will be able to encourage in their journal the publication of relevant papers on surface and solid-state properties, for it seems to be generally true that the sophistication of kinetic studies in catalytic processes has rarely been matched or accompanied by equivalently advanced investigations of the surface structures of the catalyst. It would be of great value if specialists in these fields should consider the new Journal a suitable medium for the publication of particularly relevant papers in these fields and in heterogeneous processes in general.

\section{Bulletin of the International Computation Centre}

THe first number of the I.C.C. Bulletin has just appeared. This continues the functions performed by the Bulletin of the Provisional International Computation Centre (PICC, Bulletin), and, in addition, is to act as the organ of the International Federation of Information Processing (IFIP) and will contain reports of the committees of that body $(1$, No. 1 (April 1962). Pp. vi+78. Supplement: Repertory of Computation Laboratories. Pp. 18. Rome: International Computation Centre, 1962). In addition to a new set of loose-leaf sheets describing the equipment and facilities of various computer laboratories the latest issue contains an interesting paper, by Prof. L. Collatz, on the applications of functional analysis to numerical calculation. An article on teaching machines and their simulation by a digital computer gives a picture of an automatic classroom of the future, which goes beyond the usual ideas of elementary rote instruction to a view of the way in which teaching administrators can be educated. It is an interesting and controversial essay. Among the descriptions of new machines and equipment is one of the 'IBM 1301' disk storage unit; its capacity of up to 280 million alpha-numeric symbols with a maximum access time of 0.18 sec. is likely to have important implications in the field of information storage and retrieval.

\section{European Atomic Energy Research}

THE last three issues of Atom, the monthly information bulletin of the Atomic Energy Authority, contain some articles of exceptional interest. The April issue reports Sir Leonard Owen's re-examination of nuclear power costs and Sir Roger Makin's address to the Institution of Chemical Engineers on nuclear energy in 1962. The May issue includes a long article by V. W. Eldred and K. Saddington deseribing the post-irradiation examination facilities at Windscale works, while the June issue contains a paper by J. A. Williams and P. C. Davidge of an effluent at Windscale and the effect of the civil power programme given to the British Nuclear Energy Society. It also includes a report by Dr. M. L. Smith on the symposium organized by the Central Treaty Organization Institute of Nuclear Science on the role of science in the development of natural resources with particular reference to Iran, Pakistan and Turkey (the Central Treaty Organization countries).

\section{Lasers}

ONE of the outstanding technological developments of the second half of the twentieth century is undoubtedly the use of stimulated emission for coherent generation of micro-wave radiation and light. The maser has been rapidly followed by the laser (or optical maser), and during the past two years the published literature on the latter has grown to vast 